Mario L. Ruz, Juan Garrido, Francisco Vázquez, Fernando Morilla, A hybrid modeling approach for steady-state optimal operation of vapor compression refrigeration cycles, Applied Thermal Engineering, Volume 120, 2017, pp. 74-87, ISSN 1359-4311. The Version of Record of this manuscript has been published and is available at https://doi.org/10.1016/j.applthermaleng.2017.03.103. (http://www.sciencedirect.com/science/article/pii/S1359431117303848)

\title{
A hybrid modeling approach for steady-state optimal operation of vapor compression refrigeration cycles
}

\author{
Mario L. Ruz a*, Juan Garrido a, Francisco Vázquez a, Fernando Morilla b \\ a Department of Computer Science and Numerical Analysis, University of Cordoba, Campus de \\ Rabanales, 14071 Cordoba, Spain. \\ b Department of Computer Science and Automatic Control, UNED, Juan del Rosal 16, 28040 Madrid, \\ Spain. \\ ${ }^{*}$ Corresponding author. \\ Postal address: Dpto. Informática y Análisis Numérico, Área de Ingeniería de Sistemas y \\ Automática, Universidad de Córdoba, Escuela Politécnica Superior, Campus de Rabanales, 14071, \\ Córdoba (Spain).
}

E-mail addresses: mario.ruz@uco.es (M.L. Ruz), juan.garrido@uco.es (J. Garrido), fvazquez@uco.es (F. Vázquez),fmorilla@dia.uned.es (F. Morilla).

\begin{abstract}
This paper presents a steady-state hybrid modeling approach for vapor compression refrigeration cycles which is intended to achieve an optimal system operation from an energy consumption point of view. The model development is based on a static characterization of the main components of the cycle using a hybrid approach, and their integration in a new optimization block. This block allows to determine completely the system stationary state by means of a non-linear optimization procedure subjected to several constraints such as mechanical limitations, component interactions, environmental conditions and cooling load demand. The proposed method has been tested in an experimental pilot plant with good results. Model validation for each identified hybrid model is carried out from a set of experimental data of 82 stationary operating points, with prediction errors below $\pm 10 \%$. The model is also globally validated by comparing experimental and simulated data, with a global mean relative absolute error less than $5 \%$. The basic control structure consists of three decentralized control loops where the controller variables are the secondary fluid temperature at the evaporator inlet, the superheat, and the condenser pressure. While the secondary temperature is assumed as an imposed requirement, the optimal set-points of the other two control loops are searched offline using the proposed refrigerant cycle model. This set-point optimality is defined according to the coefficient of performance for minimizing the total electrical power consumption of the system at steady-state. This energy saving has been confirmed experimentally. The proposed method can be easily adapted for different sets of controlled variables in case of modification of the basic control structure. Furthermore, other energy efficiency metrics can be handily adopted. Considering the tradeoff between the accuracy and computational cost of the hybrid models, the proposed procedure is expected to be used in real-time applications.
\end{abstract}

\section{Highlights}


- A global VCRC model is proposed based on the hybrid modeling approach.

- Extensive simulation and experimental tests are conducted to verify the accuracy of the proposed model and good agreement is observed.

- The proposed VCRC model allows for the search of optimal set-points for energy savings.

- Energy consumption reduction demonstrated using an experimental plant.

Keywords: hybrid modeling, vapor compression refrigeration cycle, parameter identification, global optimization.

\begin{tabular}{|c|c|c|c|}
\hline \multicolumn{2}{|r|}{ Nomenclature } & \multirow{2}{*}{$\begin{array}{l}T_{c, r, i, i s} \\
T_{c, s e c, i}\end{array}$} & \multirow{2}{*}{$\begin{array}{l}\text { condenser refrigerant inlet } \\
\text { temperature considering an } \\
\text { isentropic compression process } \\
(\mathrm{kJ} / \mathrm{kg})\end{array}$} \\
\hline$A_{v}$ & valve opening $(\%)$ & & \\
\hline $\begin{array}{l}a, b \\
c, f, q\end{array}$ & coefficients of hybrid models & $T_{c, r, o}$ & $\begin{array}{l}\text { condenser refrigerant outlet } \\
\text { temperature }\left({ }^{\circ} \mathrm{C}\right)\end{array}$ \\
\hline$c_{e e v}$ & expansion valve coefficient & $T_{e, r, s a t}$ & $\begin{array}{l}\text { saturated refrigerant temperature } \\
\text { in evaporator }\left({ }^{\circ} \mathrm{C}\right)\end{array}$ \\
\hline$c_{p, v}$ & $\begin{array}{l}\text { vapor specific heat at constant } \\
\text { pressure }(\mathrm{J} / \mathrm{kg} \mathrm{K})\end{array}$ & $T_{e, s e c, i}$ & $\begin{array}{l}\text { evaporator inlet temperature of } \\
\text { secondary fluid evaporator }\left({ }^{\circ} \mathrm{C}\right)\end{array}$ \\
\hline$c_{v, v}$ & $\begin{array}{l}\text { vapor specific heat at constant } \\
\text { volume }(\mathrm{J} / \mathrm{kg} \mathrm{K})\end{array}$ & $T_{\text {surr }}$ & surrounding air temperature $\left({ }^{\circ} \mathrm{C}\right)$ \\
\hline$h_{c, f g}$ & $\begin{array}{l}\text { enthalpy difference of gas and } \\
\text { liquid saturated refrigerant in } \\
\text { evaporator }(\mathrm{kJ} / \mathrm{kg})\end{array}$ & $U A$ & $\begin{array}{l}\text { global heat transfer coefficient } \\
(\mathrm{kW} / \mathrm{K})\end{array}$ \\
\hline$h_{c, r, i}$ & $\begin{array}{l}\text { condenser inlet refrigerant } \\
\text { enthalpy }(\mathrm{kJ} / \mathrm{kg})\end{array}$ & $v$ & specific volume $\left(\mathrm{m}^{3} / \mathrm{kg}\right)$ \\
\hline$h_{c, r, o}$ & $\begin{array}{l}\text { condenser outlet refrigerant } \\
\text { enthalpy }(\mathrm{kJ} / \mathrm{kg})\end{array}$ & $u$ & control signal (\%) \\
\hline$h_{c, r, i, i s}$ & $\begin{array}{l}\text { condenser refrigerant inlet } \\
\text { enthalpy considering an isentropic } \\
\text { compression process }(\mathrm{kJ} / \mathrm{kg})\end{array}$ & $\dot{W}_{c, f a n}$ & $\begin{array}{l}\text { condenser fan power consumption } \\
(\mathrm{kW})\end{array}$ \\
\hline$h_{e, r, i}$ & $\begin{array}{l}\text { evaporator inlet refrigerant } \\
\text { enthalpy }(\mathrm{kJ} / \mathrm{kg})\end{array}$ & $\dot{W}_{\text {comp }}$ & $\begin{array}{l}\text { compressor power consumption } \\
(\mathrm{kW})\end{array}$ \\
\hline$h_{e, r, g}$ & $\begin{array}{l}\text { refrigerant enthalpy of saturated } \\
\text { gas phase in evaporator }(\mathrm{kJ} / \mathrm{kg})\end{array}$ & $\rho$ & density $\left(\mathrm{kg} / \mathrm{m}^{3}\right)$ \\
\hline$h_{e, r, o}$ & $\begin{array}{l}\text { evaporator outlet refrigerant } \\
\text { enthalpy }(\mathrm{kJ} / \mathrm{kg})\end{array}$ & $\Delta$ & change, difference \\
\hline$\dot{m}_{r}$ & refrigerant mass flow rate $(\mathrm{kg} / \mathrm{s})$ & $\sigma$ & standard deviation \\
\hline$\dot{m}_{e, s e c}$ & $\begin{array}{l}\text { secondary mass flow rate in } \\
\text { evaporator }(\mathrm{kg} / \mathrm{s})\end{array}$ & Subscripts & \\
\hline$\dot{m}_{c, \sec }$ & $\begin{array}{l}\text { secondary mass flow rate in } \\
\text { condenser }(\mathrm{kg} / \mathrm{s})\end{array}$ & C & condenser \\
\hline$N$ & compressor speed (\%) & comp & compressor \\
\hline$P_{e}$ & $\begin{array}{l}\text { evaporator refrigerant saturated } \\
\text { pressure (bar) }\end{array}$ & $e$ & evaporator \\
\hline$P_{c}$ & $\begin{array}{l}\text { condenser refrigerant saturated } \\
\text { pressure (bar) }\end{array}$ & $i$ & inlet \\
\hline$\dot{Q}_{\text {comp }}$ & $\begin{array}{l}\text { mechanical work of compressor } \\
(\mathrm{kJ} / \mathrm{Kg})\end{array}$ & $o$ & outlet \\
\hline
\end{tabular}




\begin{tabular}{|l|l|l|l|}
\hline$\dot{Q}_{c}$ & $\begin{array}{l}\text { condenser energy transfer rate } \\
(\mathrm{kW})\end{array}$ & is & isentropic \\
\hline$\dot{Q}_{e}$ & $\begin{array}{l}\text { evaporator energy transfer rate } \\
(\mathrm{kW})\end{array}$ & $r$ & refrigerant \\
\hline$S_{t}$ & constant compressor coefficient & sat & saturated \\
\hline$S H$ & superheat $(\mathrm{K})$ & sec & secondary fluid \\
\hline$S C$ & subcooling $(\mathrm{K})$ & surr & surrounding \\
\hline$T_{c, r, i}$ & $\begin{array}{l}\text { condenser refrigerant inlet } \\
\text { temperature }\left({ }^{\circ} \mathrm{C}\right)\end{array}$ & & \\
\hline
\end{tabular}

\section{INTRODUCTION}

The vapor compression refrigeration cycle (VCRC) is the leading technology in cooling generation for household, commercial and industrial applications such as temperature control of buildings and automobiles for human comfort, or domestic and supermarket refrigerators for food storage and transportation [1,2]. These refrigeration processes lead to huge energy consumption and have an important economic and environmental impact as it is supported by several studies [3-5]. For instance, it is reported that about $28 \%$ of the domestic energy consumed in USA is used by these systems [6]. Other studies highlight supermarkets as one of the main energy consumers of developed countries, exceeding doubly the consumption of office buildings of similar size [7]. In addition, some reports remark that supermarket cooling systems involve about $60 \%$ of their total energy demand [8]. Therefore, the improvement of the energy efficiency of VCRC systems through process control and optimization is a key problem due to global warming and energy shortage concerns $[9,10]$.

Mostly VCRC systems consist of four main elements: two heat exchangers (evaporator and condenser), an expansion valve and a compressor $[1,11]$. These components are connected in a closed loop, as represented in Fig.1a, so that the refrigerant is continuously recirculated. The heat is transferred by the refrigerant from a space of lower temperature (cold reservoir) or from the evaporator secondary fluid to an environment of high temperature (hot reservoir) or to the condenser secondary fluid. The p-h diagram, shown in Fig. 1b, reflects the variation of the refrigerant states and ideal for the four processes involved in the cycle: isobaric evaporation, non-isentropic compression, isobaric condensation and isenthalpic expansion, explained as below.

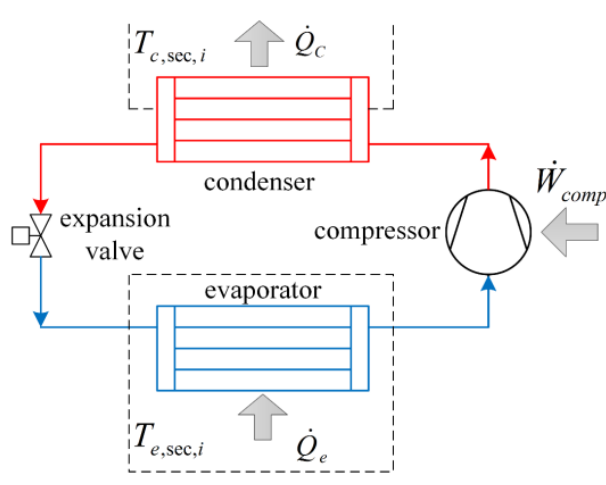

(a)
$<$ Fig. 1. IS 2 COLUMN SIZE $>$

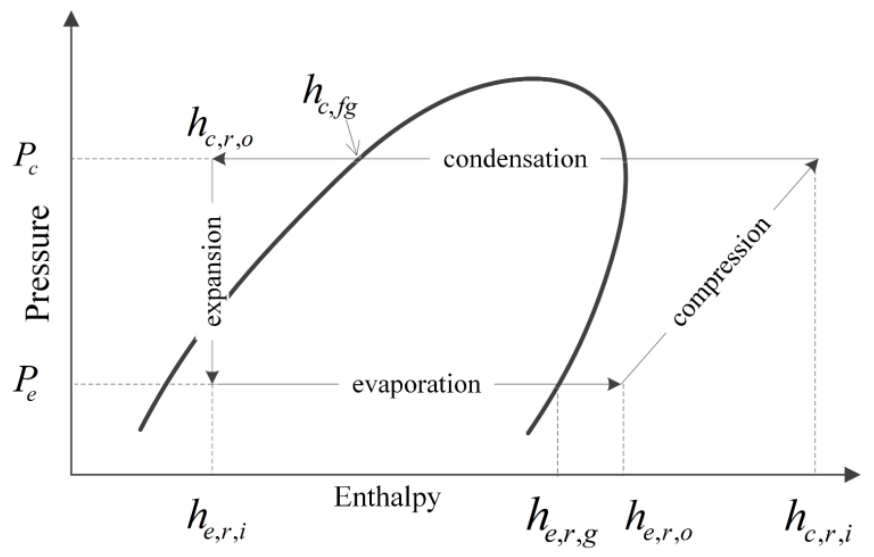

(b) 
Fig. 1. Vapor compression refrigeration cycle (a) and p-h diagram (b)

1. Starting at the evaporator inlet, the refrigerant is two-phase and its temperature is lower than that of the secondary flow; therefore, heat is removed from the secondary fluid to the refrigerant, which evaporates completely at a constant pressure. At the exit of the evaporator, the refrigerant is overheated to avoid liquid at the compressor inlet. The difference between the overheated and the saturated temperature of the refrigerant is the so-called superheat which is held low for efficiency purposes.

2. The compressor increases the temperature and pressure of the superheated vapor refrigerant by means of mechanical work.

3. Next, at the condenser, the high pressure and temperature refrigerant transfers the previous absorbed heat to the secondary fluid which has relatively lower temperature. At the condenser, the refrigerant is completely liquefied at constant pressure obtaining a subcooled liquid refrigerant at the outlet. This subcooling degree is not a free variable since it is determined by the system operation, the condenser size and the refrigerant load [12].

4. Then, the liquid phase refrigerant returns to the evaporator through the expansion valve where the pressure decreases by throttling effect to the evaporating pressure. The reduction in pressure also reduces the refrigerant temperature. That results in a two phase refrigerant at the valve outlet with low pressure and low temperature which enters the evaporator to continue the cycle.

Generally, there are three manipulated variables to operate the VCRC system: the compressor speed, the opening degree of the expansion valve and the condenser fan speed. The secondary mass flow and their inlet temperatures at evaporator and condenser act as disturbances. Most of VCRC optimization works involve the modeling of these major four components. Usually, expansion valve and compressor are statically modeled [13]. However, there are different approaches in the literature as far as evaporator and condenser are concerned. Distributed parameter models divide the heat exchanger into consecutive segments or control volumes where the outlet of one segment equals the inlet of the adjacent one. Although these models are very detailed and let analyze both static and dynamic characteristics of evaporator and condenser [14,15], they need iterative recursive calculations that make them not very suitable for control applications. The $\varepsilon$-NTU models use a dimensional parameter $\varepsilon$ (heat transfer effectiveness) to determine the static states of heat exchanger [16,17]. Other authors [18-21], divide the exchanger into several regions (one phase, two phase, superheated and subcooled sections) and apply the $\varepsilon$-NTU method for each area, simplifying the calculations. However, iterative computation and detailed geometric information are still required. On the other hand, black box models usually involve a curve fitting or identification technique that calculates the unknown parameters of the predetermined model according to experimental data. Even though they are simple and easily obtained without a great prior knowledge of the process, they usually deteriorate their performance when are extrapolated beyond the range of experimentation data $[22,23]$. The hybrid models take advantage of both empirical and physical approaches predicting the static response of the exchanger in a wide operation range with enough accuracy to be employed in real time control and optimization strategies [24-26].

The key steps for hybrid modeling development are as follows: first, the fundamental governing process equations are formulated based on an energy balance and heat transfer principles. 
Second, proper measurable inputs and controllable outputs are selected to characterize the system performance. Third, the not measurable variables of the equations are represented as functions of the previous input and output variables. Fourth, a single equation is obtained which can correlate process inputs and outputs. Finally, from experimental data and indirect calculations, the unknown parameters of the equation are identified by linear or nonlinear leastsquares techniques.

This paper is focused on the optimal steady-state operation of a VCRC system based on component hybrid modeling. Although different performance criteria can be chosen, such as the exergy efficiency $[27,28]$, in this work the optimality is defined according to the coefficient of performance (COP), which is the energy efficiency metric more accepted in the refrigeration field. The proposed approach separates the optimal operation in two problems: at low level, the VCRC is operated by means of basic PID control loops; at high level, an optimization block searches for the set-points of the previous control loops that achieve the optimal COP. It is important to note that, in some cases, the optimization stage is not directly linked with the control system. This situation occurs when the optimization degrees of freedom to drive the cycle from an arbitrary state to the optimum are different than the number of controlled variables. In such cases, a projection from the cycle space to the control space is needed [10,29]. The aim of this work is to develop a new optimization block to be available and directly linked with the basic VCRC control system, in such a way that it can bring the system from an arbitrary steady-state to the optimal one for given environmental and demand conditions. The remainder of this paper is organized as follows: Section 2 exposes the static modeling of the four main system components based on a hybrid approach and their integration into a complete VCRC model as a nonlinear constrained optimization problem. Section 3 presents the pilot plant where the experiments to verify the procedure have been performed. The parameter estimation and validation for each individual component model is detailed. A validation of the complete VCRC model is also carried out. In Section 4, the proposed approach is tested calculating the optimal references of the decentralized control system of the VCRC process for two representative stationary operation points as illustrative examples. The experimental results confirm that the COP is improved in both cases. Finally, Section 5 summarizes the conclusions and future works.

\section{HYBRID MODELS AND PARAMETER ESTIMATION}

The mathematical models of evaporator, condenser, compressor, expansion valve and the complete refrigerant cycle are described in this section. The four component models are based on the hybrid approach methodology assuming a steady-state operation. The component models are those suggested by Ding et al. [24,30], excepting the compressor model. In this case, the model developed by Schurt et al. [31] is preferred because it obtains better accuracy with similar computational cost than those proposed in other works [4,25]. All these models have characteristic parameters that need to be estimated from experimental data. The other variables must be directly measured by proper sensors (like temperatures, pressures or flows) or indirectly calculated from other data, thermodynamics tables or library functions. In this work, the CoolProp software is used [32] to obtain all properties of the refrigerant and secondary flows, such as enthalpies, entropies, densities, vapor specific heats or specific volumes.

\subsection{Evaporator}


The evaporator hybrid model developed in [24] relates the total heat transfer rate in the evaporator with the thermodynamic parameters as follows

$\dot{Q}_{e}=\frac{\left(h_{e, r, g}-h_{e, r, i}\right) \dot{m}_{r}+c_{e 1} \dot{m}_{r}^{c_{e 3}}\left(T_{e, s e c, i}-T_{e, r, s a t}\right)}{1+c_{e 2}\left(\frac{\dot{m}_{r}}{\dot{m}_{s e c}}\right)^{c_{e 3}}}$

where $T_{e, r, s a t}, h_{e, r, g}$ and $h_{e, r, i}$ are the saturation temperature, the saturation vapor enthalpy and the inlet enthalpy of the refrigerant, respectively. With this model, the total heat transfer rate is described by the function of six variables, $\dot{m}_{r}, T_{e, s e c, i}, \dot{m}_{s e c}, T_{e, r, s a t}, h_{e, g}$ and $h_{e, r, i}$, and three constants, $c_{\mathrm{e} 1}, c_{\mathrm{e} 2}, c_{\mathrm{e} 3}$. These constants are the unknown parameters that must be estimated on the basis of a set of experiments. The employed model is valid to model two-phase flow evaporators and can be used for any type fluids. In addition, it can be used for both concurrentflow and counter-flow configurations [24].

On the other hand, the heat transfer rate absorbed in the evaporator, $\dot{Q}_{e}$, meets the following energy balance equation

$\dot{Q}_{e}=\dot{m}_{r}\left(h_{e, r, o}-h_{e, r, i}\right)$

where $h_{e, r, o}$ is the refrigerant enthalpy at the evaporator outlet.

In Eq. (1), the constants $c_{\mathrm{e} 1}, c_{\mathrm{e} 2}$, and $c_{\mathrm{e} 3}$ are the only unknown parameters to be estimated in this work, since the other variables, $\dot{m}_{s e c}, T_{e, s e c, i}$ and $\dot{m}_{r}$ are measured with proper sensors, and $h_{e, r, i}, h_{e, r, g}, h_{e, r, o}$ and $T_{e, r, s a t}$ are calculated using the CoolProp library functions, providing the corresponding temperature and pressure measurements. Then, $\dot{Q}_{e}$ can be calculated according to Eq. (2). Due to $c_{\mathrm{e} 3}$, Eq. (1) is nonlinear and therefore, a nonlinear least-squares method, widely known as Levenberg-Marquardt method [33], is used. Using $n$ different operation conditions, the objective function is defined as the sum of the squares of the residuals $r_{j}$ between experimental and estimated data, as follows

$\sum_{j=1}^{n} r_{j}^{2}=\sum_{j=1}^{n}\left(\frac{\left(h_{e, r, g, j}-h_{e, r, i, j}\right) \dot{m}_{r, j}+c_{e 1} \dot{m}_{r, j}^{c_{e 3}}\left(T_{e, s e c, i, j}-T_{e, r, s a t, j}\right)}{1+c_{e 2}\left(\frac{\dot{m}_{r, j}}{\dot{m}_{s e c, j}}\right)^{c_{e 3}}}-\dot{Q}_{e, j}\right)^{2}$

\subsection{Condenser}

The hybrid model of the condenser is based on the methodology presented in Ding et al. [30]. The total heat transfer rate of the condenser can be expressed as

$\dot{Q}_{c}=\frac{c_{c 1} \dot{m}_{r}^{c} c_{c 4}\left(T_{c, r, s a t}-T_{c, s e c, i}\right)+c_{c 2} \dot{m}_{r}\left(T_{c, r, i}-T_{c, r, s a t}\right)+h_{c, f g} \dot{m}_{r}}{1+c_{c 3}\left(\frac{\dot{m}_{r}}{\dot{m}_{c, s e c}}\right)^{c_{C 4}}}$

Therefore, with this model $\dot{Q}_{c}$ is described by the function of six variables, $T_{c, r, s a t}, \dot{m}_{r}, T_{c, s e c, i}$, $\dot{m}_{c, s e c}, T_{c, r, s a t}$ and $h_{c, f g}$, that can be measured or indirectly calculated in the similar way than in the evaporator case.

The corresponding balance equation in this case is 
$\dot{Q}_{c}=\dot{m}_{r}\left(h_{c, r, i}-h_{c, r, o}\right)$

where $h_{c, r, i}$ and $h_{c, r, o}$ represent the inlet and outlet enthalpies of the refrigerant at the condenser, respectively.

In this model, the four constants $c_{\mathrm{c} 1}, c_{\mathrm{c} 2}, c_{\mathrm{c} 3}$ and $c_{\mathrm{c} 4}$ must be estimated based on experimental data of the aforementioned seven variables. As for the evaporator case, Eq. (4) is nonlinear and a nonlinear least-squares method must be used. Using $n$ experimental operation points, the objective function is similarly defined as follows

$\sum_{j=1}^{n} r_{j}^{2}=\sum_{j=1}^{n}\left(\frac{c_{c 1} \dot{m}_{r, j}^{c_{c 4}}\left(T_{c, r, s a t, j}-T_{c, s e c, i, j}\right)+c_{c 2} \dot{m}_{r, j}\left(T_{c, r, i, j}-T_{c, r, s a t, j}\right)+h_{c, f g, j} \dot{m}_{r, j}}{1+c_{c 3}\left(\frac{\dot{m}_{r, j}}{\dot{m}_{c, s e c, j}}\right)^{c_{c 4}}}-\dot{Q}_{c, j}\right)^{2}$

The secondary air mass flow is estimated according to a linear expression of the flow multiplied by the air density, as follows

$\dot{m}_{c, \text { sec }}=\rho_{\text {air }, T_{c, \text { sec }, i}}\left(q_{1} u_{\%}+q_{2}\right)$

where $u_{\%}$ represents the input signal to the condenser fan, and $q_{1}$ and $q_{2}$ are estimated parameters from experimental measurements. The air density is calculated with CoolProp functions and depends on the measured air temperature.

A quadratic model for the estimation of the electrical power consumption of the fan is used. This model provides the absorbed active power as a function of the signal input of the variable frequency drive. The coefficients can be fitted to experimental data as part of the model validation exercise. The fan power consumption at the condenser is modeled as follows

$\dot{W}_{c, f a n}=f_{1} u_{\%}^{2}-f_{2} u_{\%}+f_{3}$

where $f_{1}, f_{2}$ and $f_{3}$ are estimated parameters from experimental data.

\subsection{Compressor}

The compressor provides the refrigerant mass flow rate suctioned from the evaporator and discharged to the condenser [25], the electrical power consumed by the compression process [31], and the energy obtained by the refrigerant [31,34]. The mass flow rate $\dot{m}_{r}$ and the electrical power consumed $\dot{W}_{\text {comp }}$ are given by the following equations [31]

$$
\begin{aligned}
& \dot{m}_{r}=S_{t} N\left(1-c\left(\left(\frac{P_{c}}{P_{e}}\right)^{\frac{c_{v, v}}{c_{p, v}}}-1\right)\right) v^{-1} \\
& \dot{W}_{\text {comp }}=a+b \dot{m}_{r}\left(h_{c, r, i, i s}-h_{e, r, o}\right)
\end{aligned}
$$

where $c_{v, v}$ and $c_{p, v}$ are calculated from the saturated vapor at the evaporating pressure, $P_{e}$, and $S_{t}, c, a$ and $b$ are the parameters to be estimated from experimental data. The other variables $\left(\dot{m}_{r}, P_{c}, P_{e}\right.$ and $\left.\dot{W}_{c o m p}\right)$ must be measured directly using proper sensors or indirectly $\left(v, c_{v, v}\right.$, $c_{p, v}, h_{e, r, o}$ and $\left.h_{c, r, i, i s}\right)$ calculated from thermodynamics functions of CoolProp. As mentioned before and as observed in Eq. (10), the compressor model requires the calculation of $h_{c, r, i, i s}$, i.e., the refrigerant inlet enthalpy at the condenser considering an isentropic compression 
process. This variable is obtained as a function of $P_{c}, P_{e}$ and $h_{e, r, o}$. The refrigerant entropy at the evaporator outlet is calculated as a function of $P_{e}$ and $h_{e, r, o}$, and imposed as the condenser inlet entropy.

The relationship between the electrical power input to the compressor and the energy obtained by the refrigerant, $\dot{Q}_{c o m p}$, is given by [31]

$\dot{Q}_{\text {comp }}=\dot{W}_{\text {comp }}-U A\left(T_{c, r, i, i s}-T_{\text {surr }}\right)$

where $T_{\text {surr }}$ is the measured surrounding temperature, $U A$, the global heat transfer constant of the compressor and $T_{c, r, i, i s}$, the corresponding temperature to $h_{c, r, i, i s}$. $\dot{Q}_{c o m p}$ can be estimated according to the following energy balance equation

$\dot{Q}_{c o m p}=\dot{m}_{r}\left(h_{c, r, i}-h_{e, r, o}\right)$

Equations (9), (10) and (11) are linear on their corresponding unknown parameters St, $c, a, b$ and UA. Therefore, a linear least-squares method can be directly applied for $n$ samples under different operation conditions. For instance, Eq. (9) can be expressed in the linear matrix form $\Psi \cdot \mathrm{X}=\Gamma+\Delta$, where $\mathrm{X}=\left[S_{t}\left(c \cdot S_{t}\right)\right]^{T}, \Delta$ are measurement errors, and

$\Psi=\left[\begin{array}{cc}N_{1} v_{1}^{-1} & -N_{1} v_{1}^{-1}\left(\left(\frac{P_{c 1}}{P_{e 1}}\right)^{\frac{c_{v, v 1}}{c_{p, v 1}}}-1\right) \\ N_{2} v_{2}^{-1} & -N_{2} v_{2}^{-1}\left(\left(\frac{P_{c 2}}{P_{e 2}}\right)^{\frac{c_{v, v 2}}{P_{p, v 2}}}-1\right) \\ \vdots & \vdots \\ N_{n} v_{n}^{-1} & -N_{n} v_{n}^{-1}\left(\left(\frac{P_{c n}}{P_{e n}}\right)^{\frac{c_{v, v n}}{c_{p, v n}}}-1\right)\end{array}\right]$

$\Gamma=\left[\begin{array}{c}\dot{m}_{r 1} \\ \dot{m}_{r 2} \\ \vdots \\ \dot{m}_{r n}\end{array}\right]$

In this case, the best estimation of $\mathrm{X}$ can be obtained as follows

$X=\left(\Psi^{T} \Psi\right)^{-1} \Psi^{T} \Gamma$

The problem resolution for $\dot{W}_{\text {comp }}$ can be formulated similarly with $\mathrm{X}=\left[\begin{array}{ll}a & b\end{array}\right]^{T}$ as parameters and the following matrices

$\begin{aligned} \Psi & =\left[\begin{array}{cc}1 & \dot{m}_{r 1}\left(h_{c, r, i, i s 1}-h_{e, r, o 1}\right) \\ 1 & \dot{m}_{r 2}\left(h_{c, r, i, i s 2}-h_{e, r, o 2}\right) \\ \vdots & \vdots \\ 1 & \dot{m}_{r n}\left(h_{c, r, i, i s n}-h_{e, r, o n}\right)\end{array}\right] \\ \Gamma & =\left[\begin{array}{c}\dot{W}_{c o m p 1} \\ \dot{W}_{c o m p 2} \\ \vdots \\ \dot{W}_{c o m p n}\end{array}\right](17)\end{aligned}$ 
Finally, for the case of Eq. (11), $X=U A$ and

$\Psi=\left[\begin{array}{c}T_{c, r, i, i s 1}-T_{\text {surr } 1} \\ T_{c, r, i, i s 2}-T_{\text {surr } 2} \\ \vdots \\ T_{c, r, i, i s n}-T_{\text {surr }}\end{array}\right]$

$\Gamma=\left[\begin{array}{c}\dot{W}_{c o m p 1}-\dot{Q}_{c o m p 1} \\ \dot{W}_{c o m p 2}-\dot{Q}_{c o m p 2} \\ \vdots \\ \dot{W}_{c o m p n}-\dot{Q}_{c o m p n}\end{array}\right]$

\subsection{Expansion valve}

Regarding the expansion valve model [25], the refrigerant mass flow rate through it is calculated from the orifice equation

$\dot{m}_{r}=c_{e e v} A_{v} \sqrt{\rho_{r}\left(P_{c}-P_{e}\right)}$

The mass flow rate, $\dot{m}_{r}$, is described by the function of four variables: the valve opening area, $A_{v}$, the pressure difference across the expansion valve, $\Delta P$, the density of the refrigerant at the valve inlet, $\rho_{v}$, and a constant, $c_{e e v}$.

The $c_{e e v}$ constant is the only parameter which needs to be determined assuming that the other variables can be measured directly using proper sensors or indirectly from thermodynamics tables. For instance, $\rho_{v}$ can be calculated using CoolProp when $P_{e}$ and $T_{e}$ are measured, and $A_{v}$ is imposed. Then, since Eq. (20) is linear on $c_{e e v}$, a liner least-squares method can be directly applied similarly to the compressor case, where $\mathrm{X}=c_{e e v}, \Delta$ are measurement errors, and

$\Psi=\left[\begin{array}{c}A_{v 1} \sqrt{\rho_{v 1} \Delta P_{1}} \\ A_{v 2} \sqrt{\rho_{v 2} \Delta P_{2}} \\ \vdots \\ A_{v n} \sqrt{\rho_{v 2} \Delta P_{n}}\end{array}\right]$

$\Gamma=\left[\begin{array}{c}\dot{m}_{r 1} \\ \dot{m}_{r 2} \\ \vdots \\ \dot{m}_{r n}\end{array}\right]$

2.5 Vapor compression refrigerant cycle model as an optimization problem

After defining the equations for each component, the steady-state of the VCRC is given by a system of coupled nonlinear equations subjected to a set of constraints. To solve this system, some variables are assumed to be known, such as those related with environmental conditions or disturbances. Others variables need to be imposed to find a model solution and then estimating the rest of unknown variables. Usually, the number of imposed variables equals the degrees of freedom of the system, that is, the number of manipulated variables. Then, the set of nonlinear equations is generally solved using some iterative procedure as reported by several works, where two approaches are traditionally differentiated, the simultaneous and the sequential solving methods [35-37]. In the first approach each dependent variable is solved prior to moving on the next unknown variable. The second approach uses a multi-variable nonlinear 
equation solver where the unknown variables are resolved simultaneously. In either case, the imposed independent variables are different depending on the algorithm. For this variable selection, most works deal with reducing the process complexity and improving the solution accuracy.

In this work, a simultaneous iterative procedure is proposed from the previous component equations. This method tries to determine the unknown variables by minimizing the weighted quadratic residuals in eight different interaction equations and fulfilling several physical constraints of the components. The objective function can be formulated as

Minimize $J=\sum_{i=1}^{8} w_{i} r_{i}^{2}$

where the first seven ri are the residuals of the previous component equations for the refrigerant mass flow rate at the expansion valve, the refrigerant mass flow rate and the power $\dot{\mathrm{Q}}_{\text {comp }}$ obtained at the compressor, and the heat transfer rates at the evaporator and condenser, $\dot{\mathrm{Q}}_{\mathrm{e}}$ and $\dot{\mathrm{Q}}_{\mathrm{c}}$, respectively. Specifically, equations (1), (2), (4), (5), (9), (11) and (20) are involved. The last residual, the eighth one, represents the energy rate balance of the overall cycle and is given by

$r_{8}=\dot{Q}_{c}-\dot{Q}_{e}-\dot{Q}_{c o m p}$

The weights $w_{i}$ are chosen in order to obtain residuals with similar magnitude. This minimization problem is subjected to physical and technological constraints in a given specific equipment. Maximum and minimum values for the variables $\dot{m}_{r}, \dot{m}_{e, s e c}, A_{v}, N, P_{e}, P_{c}, \dot{Q}_{c}, \dot{Q}_{c o m p}, h_{e, r, o}, h_{c, r, o}$ and $h_{c, r, i}$ are considered according to the corresponding normal operation range of the system. Furthermore, auxiliary variables such as the subcooling ( $\mathrm{SC}$ ) and the superheat ( $\mathrm{SH}$ ), also must fulfill this requirement. The expressions for subcooling and superheat are the following

$$
\begin{aligned}
& S H=T_{e, r, o}-T_{e, r, s a t} \\
& S C=T_{c, r, s a t}-T_{c, r, o}
\end{aligned}
$$

In addition, in order to take into account other physical limitations and to improve the accuracy of the solution, other constraints are considered as well. At the evaporator and condenser, the temperature difference between primary and secondary flows must be greater than a minimum value in order to heat exchange takes place. This is represented in the following constraints

$T_{e, s e c, i}-T_{e, r, s a t} \geq \Delta T_{e, \min }$

$T_{c, r, s a t}-T_{c, s e c, i} \geq \Delta T_{c, \min }$

where $\Delta T_{e, \min }$ and $\Delta T_{c, \min }$ are the minimum necessary temperature difference at the evaporator and condenser, respectively. At the condenser, the output temperature also needs to fulfill

$T_{c, r, o} \geq T_{c, s e c, i}$

The proposed procedure is represented in the schematic of Fig. 2, where the relationship between the component parameters is shown. The variables $\dot{m}_{e, s e c}, T_{c, \text { sec }, i}, T_{\text {surr }}$ and $\dot{Q}_{e}$ are considered as disturbances that must be measured directly or indirectly. As it is detailed later, the experimental plant in this work is configured with three PI control loops: the evaporator 
secondary temperature $T_{e, s e c, i}$ is controlled by the compressor speed $N$; the condensation pressure $P_{c}$, by the fan (the secondary air flow $\dot{m}_{c, s e c}$ ); and the superheat $S H$, by the expansion valve opening degree $A_{v}$. Because of the integral action of PI controllers, these controlled variables will achieve their corresponding references at stationary state with zero error. Therefore, the variables $T_{e, s e c, i}, P_{c}$ and $S H$ are also assumed to be known as their corresponding imposed set-points. In order to use the superheat as an imposed variable, Eq. (25) must be incorporated in the model as an additional constraint. For the rest of the unknown variables, initial values must be considered. Then, the different residuals of $\dot{m}_{r}, \dot{Q}_{e}, \dot{Q}_{c}$ and $\dot{Q}_{c o m p}$ are simultaneously calculated and the value $J$ of expression (23) is obtained. Using these results and taking into account the system constraints, a global correction process is performed updating the value of the initial unknown variables. This procedure is iterated until a proper solution accuracy is achieved. The solution convergence of the nonlinear and constrained equation system (correction block shown in Fig. 2) is based on an interior-point method [38]. Maximum allowed tolerances must be established for the residuals. If no solution fulfils these tolerances, it is assumed that the VCRC cannot work under the imposed conditions.

Note that the proposed imposed variables in this work can be modified according to different control loops. In addition, although Fig. 2 highlights the variable interactions between the set of equations that constitutes the proposed VCRC model, it is important to note that the residual errors of the dependent variables are minimized simultaneously by means of Eq. (23). When a specified minimum threshold of the aforementioned equation is crossed, convergence is met and thus a solution is found for the constrained nonlinear system. Usually, many of the researches related with VCRC simulations are focused on the model convergence, i.e., to study solver characteristics such as robustness and convergence speed [35]. One of the main purposes of this work is to apply the developed model to real cases by means of the experimental plant described in the next section. After several tests, the simultaneous approach was considered due to the difficulties found when applying sequential solving methods. The latter case was also tested with a sequential algorithm, and although the algorithm also converges, the solution is sometimes very different when compared with the experimental results obtained under the same conditions, or even not reachable with the experimental plant. The total number of parameters and variables used in the proposed optimization problem are detailed in the next section.

$<$ Fig.2. IS 2 COLUMN SIZE $>$ 


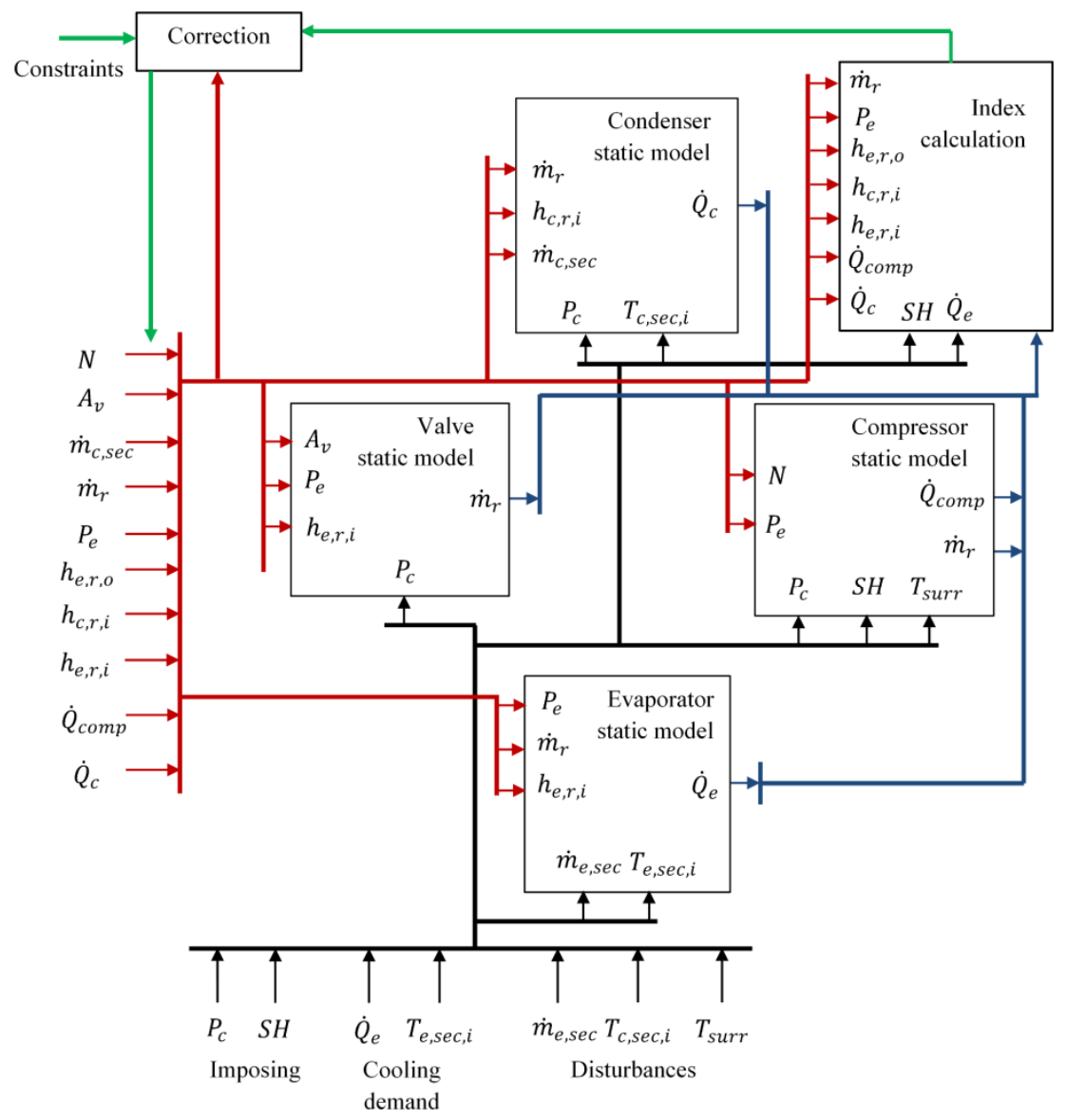

Fig. 2. Schematic procedure of the VCRC model proposed as an optimization problem

\section{EXPERIMENTAL SETUP}

In this section, the previous hybrid component models and the VCRC model are used to characterize a pilot refrigerant plant. After describing the system, a parameter identification process and model validation is carried out from a set of experimental data of 82 stationary operating points. First, the parameter estimation of each component is presented. Next, each component is separately validated and then, a global validation is performed for the complete VCRC model proposed previously which integrates the four components.

\subsection{Plant description}

The experimental plant, shown in Fig. 3, is located in the Research Laboratory of Automation and System Engineering at the University of Cordoba. It consists of three clearly differentiated subsystems (for more information see [39]):

- One-stage VCRC system. This subsystem consists of a one-stage semi-hermetic piston compressor (Bitzer 2JES-07Y model) for R-134a refrigerant, a brazed plate heat exchanger (Sweep B15THX20-1P) as the evaporator, an electronic expansion valve (Carel E2V11) and a finned tube bundle as condenser (ad-hoc model). The condenser incorporates a centrifugal extractor which allows floating condensation. Its secondary fluid is air cooled or heated from the outdoor air temperature emulation system. 
- Outdoor air temperature emulation subsystem. This subsystem is composed of a packaged reversible air-cooled water chiller which keeps constant the temperature of a water buffer tank of 3001 , a regulated mixing valve, an hydraulic pump and an aircooled condenser (condenser 1 in Fig. 4) located before the VCRC condenser. The buffer tank acts as intermediate point between the air-cooled water chiller and the condenser circuit. The condenser circuit is fed with hot or cool water from the storage tank. This water flow before the condenser causes a variation in the inlet air of the VCRC condenser (T5), which is regulated by a PI controller. The manipulated variable of this controller is the opening degree of the mixing valve. The secondary fluid of condenser 2 is the air from the surroundings where the pilot plant is installed.

- Thermal load emulation subsystem. The secondary fluid in the evaporator is a brine of around $40 \%$ ethylene glycol aqueous solution, which circulates through a small tank. An electrical resistance is inserted inside the tank. The power supplied by the resistance is controlled by a solid state relay. The secondary circuit in the evaporator also contains a hydraulic pump that controls the secondary flow rate to the evaporator. As the heat load can be modified by the resistance, the cooling demand $\dot{Q}_{e}$ can be consequently imposed and therefore, it is possible to analyze the performance of the system with very different real scenarios.

The main components and sensor locations of the experimental plant are shown in the diagram of Fig. 4. The system incorporates a flowmeter in the liquid line which measures the liquid refrigerant volumetric flow. The condenser fan, the compressor and the glycol hydraulic pump are equipped with variable frequency drives (VFD) to regulate the air speed, refrigerant and brine flow rates. The three PI control loops mentioned in Section 2, the PI control loop of the temperature emulation subsystem, and all the software needed to run the experimental campaigns are implemented in a Programmable Logic Controller (PLC). This PLC is also connected with a PC where all the variables of interest are monitored and automatically collected by a supervisory control and data acquisition system. The $\mathrm{p}$-h diagram is also calculated using CoolProp functions and plotted in real time. In order to identify the steadystate points, the collected data were post-processed with Matlab software. A sampling period of $5 \mathrm{~s}$ was applied during the campaigns.

$<$ Fig. 3. IS 2 COLUMN SIZE $>$

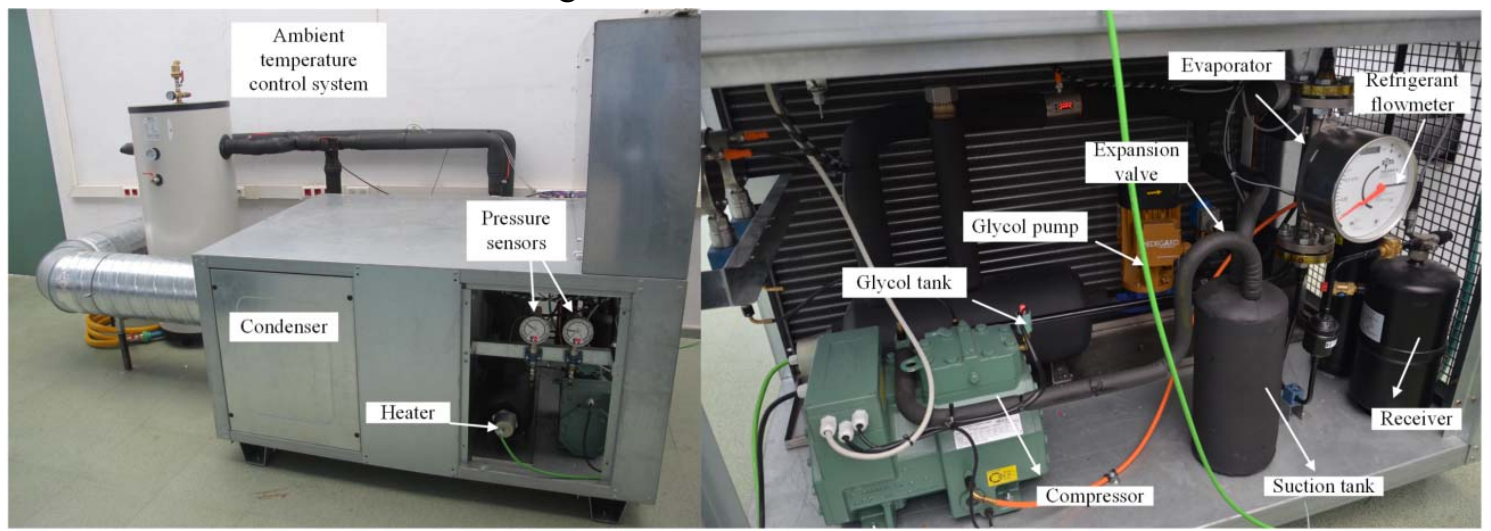

Fig. 3. Main components of the experimental plant 
$<$ Fig. 4. IS 2 COLUMN SIZE $>$

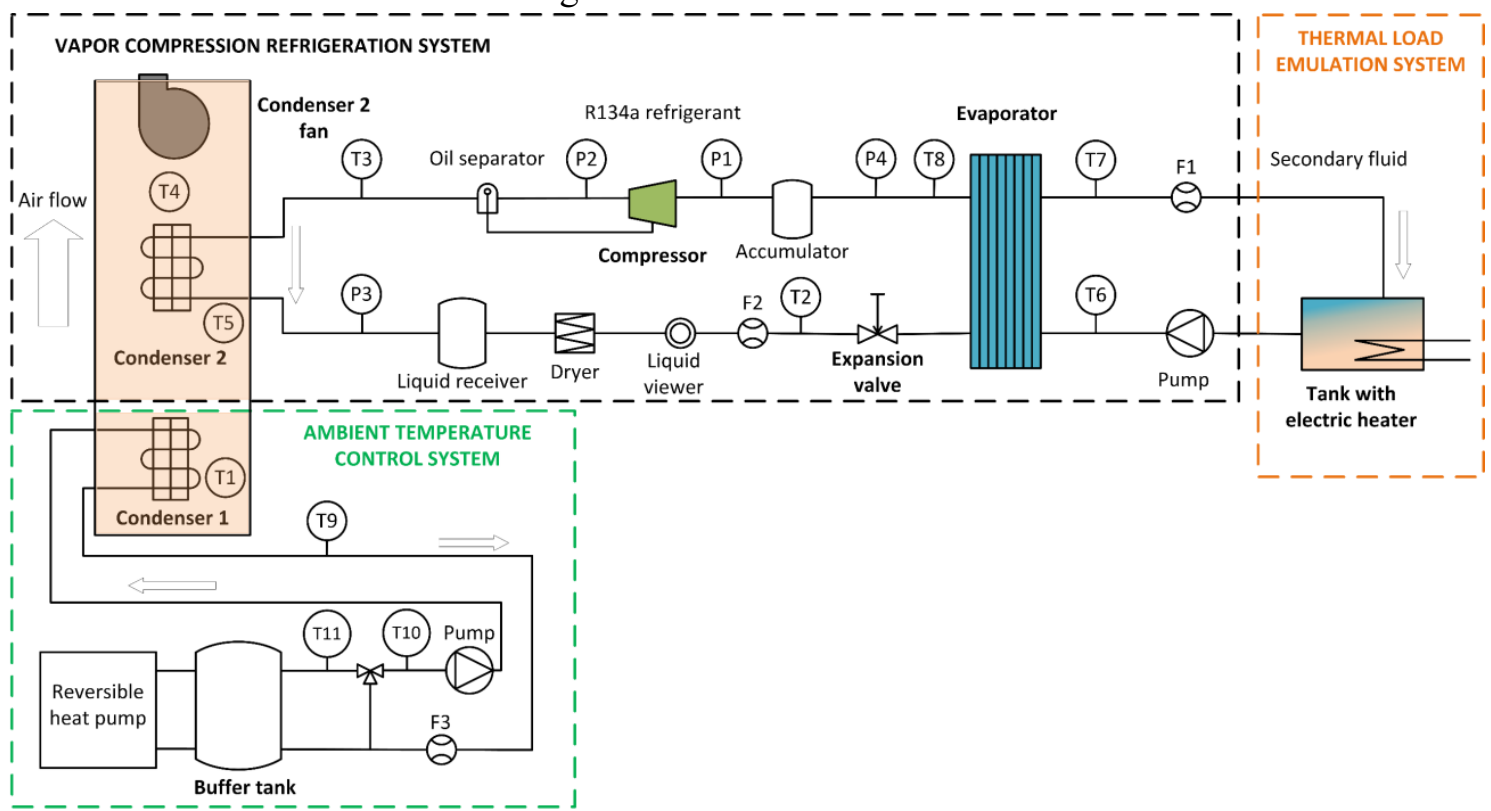

Fig. 4. Schematic diagram of the experimental system

Table 1 lists the range of operating conditions in which the hybrid models have been obtained. The specified bounds are extracted from the 82 steady-state analyzed points. As can be seen from the table, and considering the solution strategy described in Section 2.5, the variables have been classified into four categories:

- Dependent variables $\left(A_{v}, h_{e, r, o}, h_{c, r, i}, h_{c, r, o}, \dot{m}_{r}, \dot{m}_{c, s e c}, N, P_{e}, \dot{Q}_{c}, \dot{Q}_{c o m p}\right)$ : These variables constitute the output solution of the proposed VCRC model. They are resolved considering the constraints specified in Section 2 as well as the range of operating conditions specified in Table 1 .

- Bijective variables (SC, $\left.\dot{W}_{c o m p}, T_{c, r, o}\right)$ : The values of these variables are calculated from the model solution.

- Independent variables $\left(P_{c}, \mathrm{SH}, T_{e, s e c, i}\right)$ : These variables are specified within the constraint limits.

- Uncontrollable variables $\left(\dot{m}_{e, s e c}, \dot{Q}_{e}, T_{c, s e c, i}, T_{\text {surr }}\right)$ : They are considered to be determined by user demand or external conditions.

Table 1. Range of operating conditions

\begin{tabular}{|c|l|l|l|}
\hline Variable & Lower bound & Upper bound & Units \\
\hline $\begin{array}{l}\text { Dependent } \\
\text { variables }\end{array}$ & & & \\
\hline$A_{v}$ & 0 & 100 & $\%$ \\
\hline$h_{e, r, o}$ & 398.16 & 405.31 & $\mathrm{~kJ} / \mathrm{kg}$ \\
\hline$h_{c, r, i}$ & 445.12 & 461.49 & $\mathrm{~kJ} / \mathrm{kg}$ \\
\hline$h_{c, r, o}$ & 226.69 & 252.87 & \\
\hline$\dot{m}_{r}$ & $5.65 \cdot 10^{-3}$ & $16.38 \cdot 10^{-3}$ & $\mathrm{~kg} / \mathrm{s}$ \\
\hline$\dot{m}_{c, s e c}$ & $0.65 \cdot 10^{-3}$ & $2.19 \cdot 10^{-3}$ & $\mathrm{~kg} / \mathrm{s}$ \\
\hline$N$ & $60(35)$ & $100(50)$ & $\%(\mathrm{~Hz})$ \\
\hline$P_{e}$ & 1.75 & 3.21 & $\mathrm{bar}$ \\
\hline$\dot{Q}_{c}$ & 1.21 & 3.32 & $\mathrm{~kW}$ \\
\hline
\end{tabular}




\begin{tabular}{|c|l|l|l|}
\hline$\dot{Q}_{\text {comp }}$ & 0.26 & 0.72 & $\mathrm{~kW}$ \\
\hline $\begin{array}{l}\text { Bijective } \\
\text { variables }\end{array}$ & & & \\
\hline $\mathrm{SC}$ & 13.8 & 18.2 & $\mathrm{~K}$ \\
\hline$T_{c, r, i}$ & 61.3 & 84.5 & ${ }^{\circ} \mathrm{C}$ \\
\hline$\dot{W}_{\text {comp }}$ & 0.43 & 0.86 & $\mathrm{~kW}$ \\
\hline$\dot{W}_{c, \text { fan }}$ & 0.31 & 0.99 & $\mathrm{~kW}$ \\
\hline $\begin{array}{l}\text { Independent } \\
\text { variables }\end{array}$ & & & \\
\hline$P_{c}$ & 8.61 & 14.52 & $\mathrm{bar}$ \\
\hline SH & 5 & 15 & $\mathrm{~K}$ \\
\hline$T_{e, \text { sec }, i}$ & -10 & 5 & ${ }^{\circ} \mathrm{C}$ \\
\hline $\begin{array}{l}\text { Uncontrollable } \\
\text { variables }\end{array}$ & & & \\
\hline$\dot{m}_{e, \text { sec }}$ & $84.23 \cdot 10^{-3}$ & $355.79 \cdot 10^{-3}$ & $\mathrm{~kg} / \mathrm{s}$ \\
\hline$\dot{Q}_{e}$ & 0.4 & 1.9 & $\mathrm{~kW}$ \\
\hline$T_{c, \text { sec }, i}$ & 8.9 & 39.9 & ${ }^{\circ} \mathrm{C}$ \\
\hline$T_{\text {surr }}$ & 19 & 34.3 & ${ }^{\circ} \mathrm{C}$ \\
\hline
\end{tabular}

\subsection{Identification of component models}

From the previous conducted experiments, the identification of the constant parameters of the component models described in Section 2 is performed using 54 steady-states. For this purpose, the aforementioned linear and nonlinear least squares methods exposed in Section 2 have been applied. The resultant parameters are collected in Table 2 .

Table 2. Estimated parameters of models

\begin{tabular}{|c|c|c|c|c|c|c|c|c|c|}
\hline \multirow{2}{*}{$\begin{array}{l}\text { Component } \\
\text { Parameter }\end{array}$} & \multicolumn{3}{|c|}{ Evaporator } & \multicolumn{5}{|c|}{ Compressor } & \multirow{2}{*}{$\begin{array}{c}\begin{array}{c}\text { Expansion } \\
\text { valve }\end{array} \\
c_{\text {eev }}\end{array}$} \\
\hline & $c_{e 1}$ & $c_{e 2}$ & $c_{e 3}$ & $S_{t}$ & $c$ & $a$ & $b$ & $U A$ & \\
\hline Value & 3.0953 & 0.0500 & 1.01819 & $1.4265 \cdot 10^{-5}$ & 0.0902 & 0.2272 & 1.2241 & 0.00465 & $2.1724 \cdot 10^{-6}$ \\
\hline Component & \multicolumn{9}{|c|}{ Condenser } \\
\hline Parameter & $c_{c 1}$ & $c_{c 2}$ & $c_{c 3}$ & $c_{c 4}$ & $f_{1}$ & $f_{2}$ & $f_{3}$ & $q_{1}$ & $q_{2}$ \\
\hline Value & 2.8550 & 1.0876 & 4.4216 & 1.0611 & 0.00020 & 0.01495 & 0.59030 & 0.01950 & 0.04153 \\
\hline
\end{tabular}

The fitting results of the estimated models and the relative errors of each operation point are shown in Fig. 5 and Fig. 6, respectively. In order to evaluate the performance of the models, Table 3 also collects the mean relative error $E_{R}$, the root mean square error $E_{R M S}$, and the adjusted coefficient of determination $\mathrm{R}^{2}$ for each estimated variable. The prediction errors of the models are below $\pm 10 \%$ and the coefficient of determination indicates a goodness of fit above $90 \%$ or greater. 

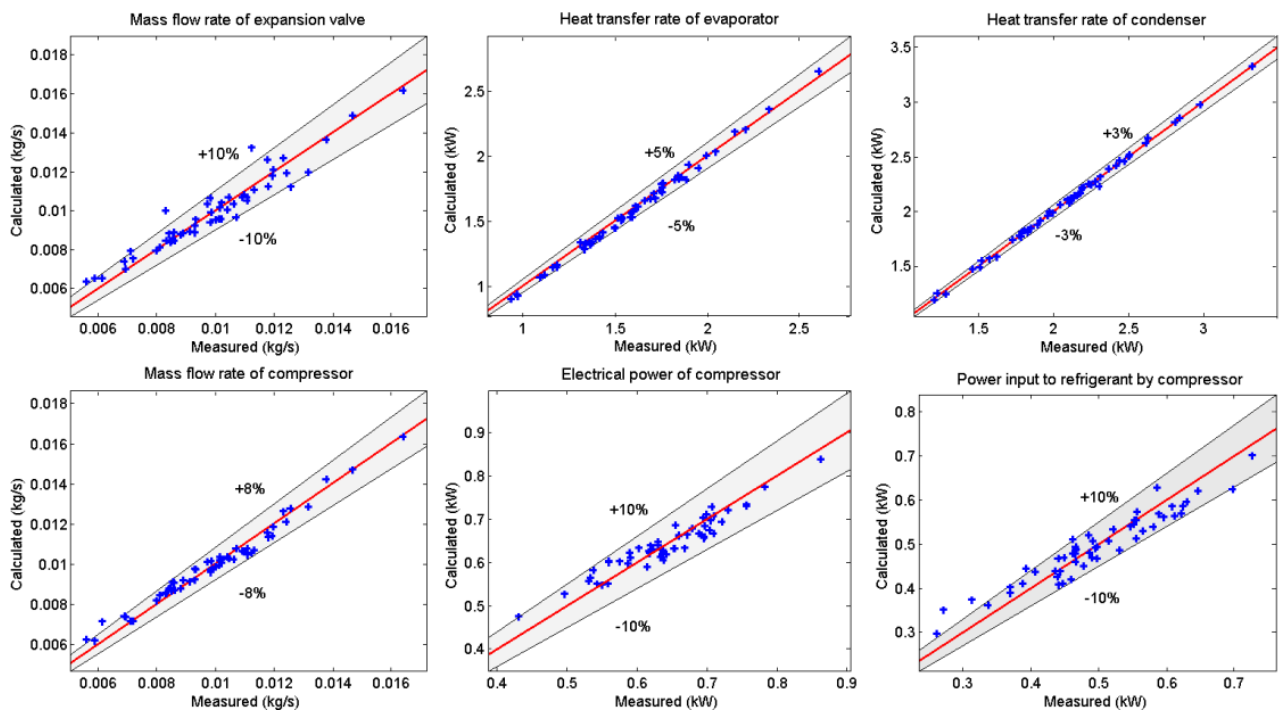

Fig.5. Experiment fitting of component model identification
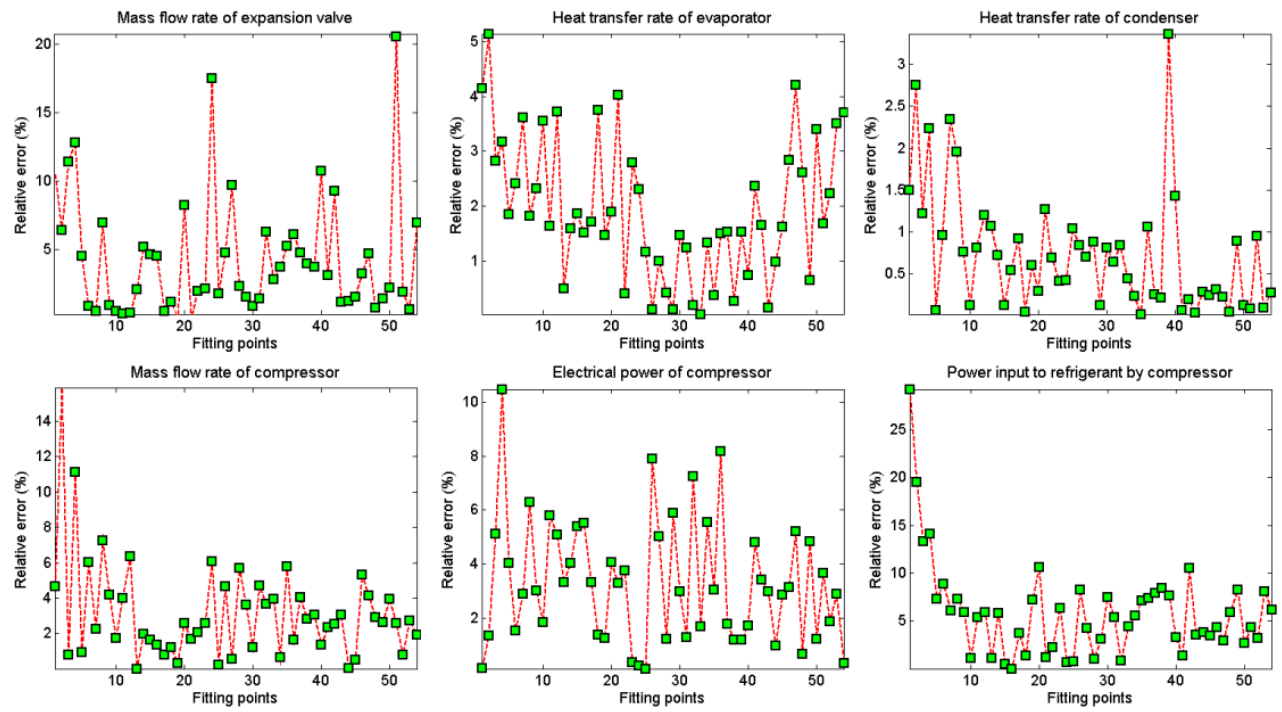

Fig. 6. Relative errors of component model identification

Table 3. Performance indices for component model identification

\begin{tabular}{|c|c|c|c|c|c|c|c|}
\hline Variable & $\begin{array}{c}\dot{m}_{r} \\
\text { (valve) }\end{array}$ & $\dot{Q}_{e}$ & $\dot{Q}_{c}$ & $\begin{array}{c}\dot{m}_{r} \\
\text { (comp) }\end{array}$ & $\dot{W}_{\text {comp }}$ & $\dot{Q}_{\text {comp }}$ & $\dot{W}_{c, \text { fan }}$ \\
\hline$E_{R}(\%)$ & 4.31 & 1.94 & 0.73 & 3.16 & 3.30 & 5.85 & 0.92 \\
\hline$E_{R M S}$ & 6.11 & 2.31 & 1.02 & 4.18 & 4.05 & 7.61 & 1.14 \\
\hline$R^{2}(\%)$ & 92.42 & 99.00 & 99.79 & 97.23 & 89.85 & 88.9 & 99.71 \\
\hline
\end{tabular}

As can be noted from Fig. 6, there are some points where the relative error is greater. This occurred in those cases where the imposed operation point in the experimental plant was near to the one or more of the range limits specified in Table 1.

\subsection{Validation of component models}

To verify the effectiveness of the identified models, they are separately validated using the other 28 different stationary operation points. To make a comparison between the measured values and the model estimated values, a curve fit representation is shown in Fig. 7, similarly to the 
preceding section. In addition, Fig. 8 presents the relative errors for each model and each point. Table 4 summarizes the resultant mean relative errors, root mean square errors and the adjusted coefficients of determination $\mathrm{R}^{2}$ of each variable. These values are similar to those obtained for estimation. Within the operation range, the errors of the models are small in comparison with the measured data, and the predicted values look reasonable. The greatest errors occur again at points close to the operating limits.

$<$ Fig. 7 AND 8 ARE 2 COLUMN SIZE $>$
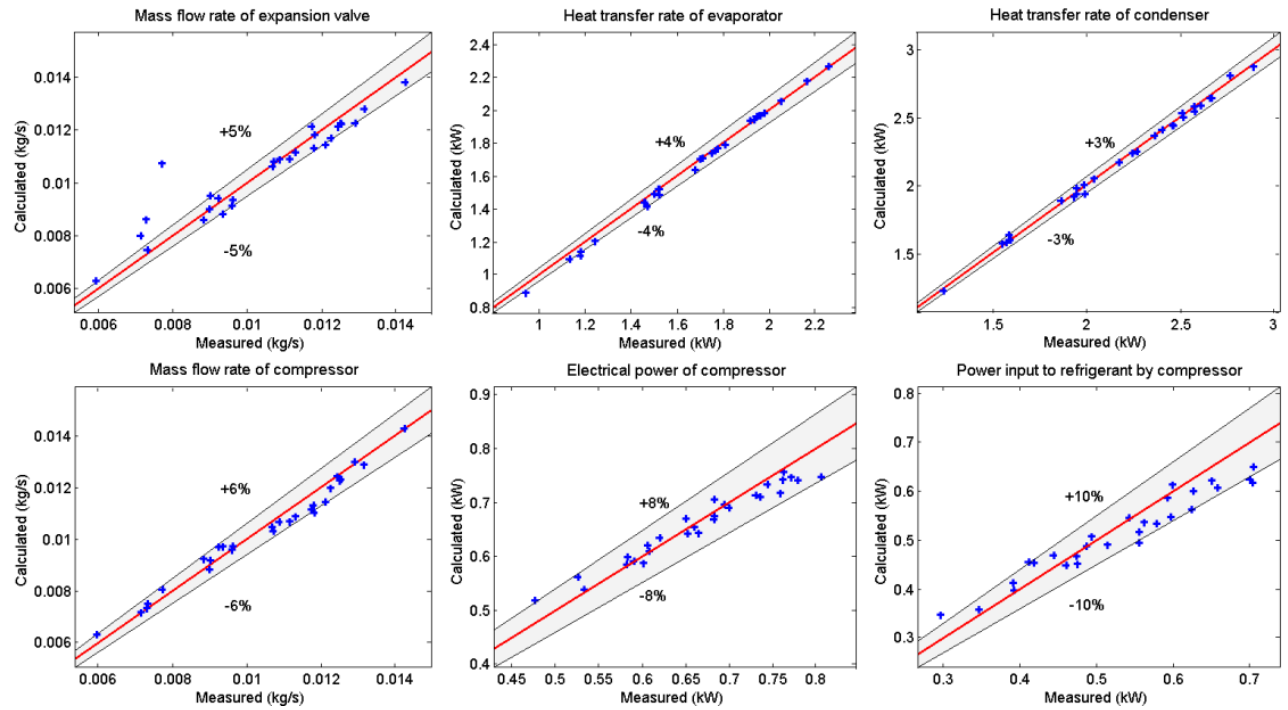

Fig. 7. Experiment fitting of component model validation
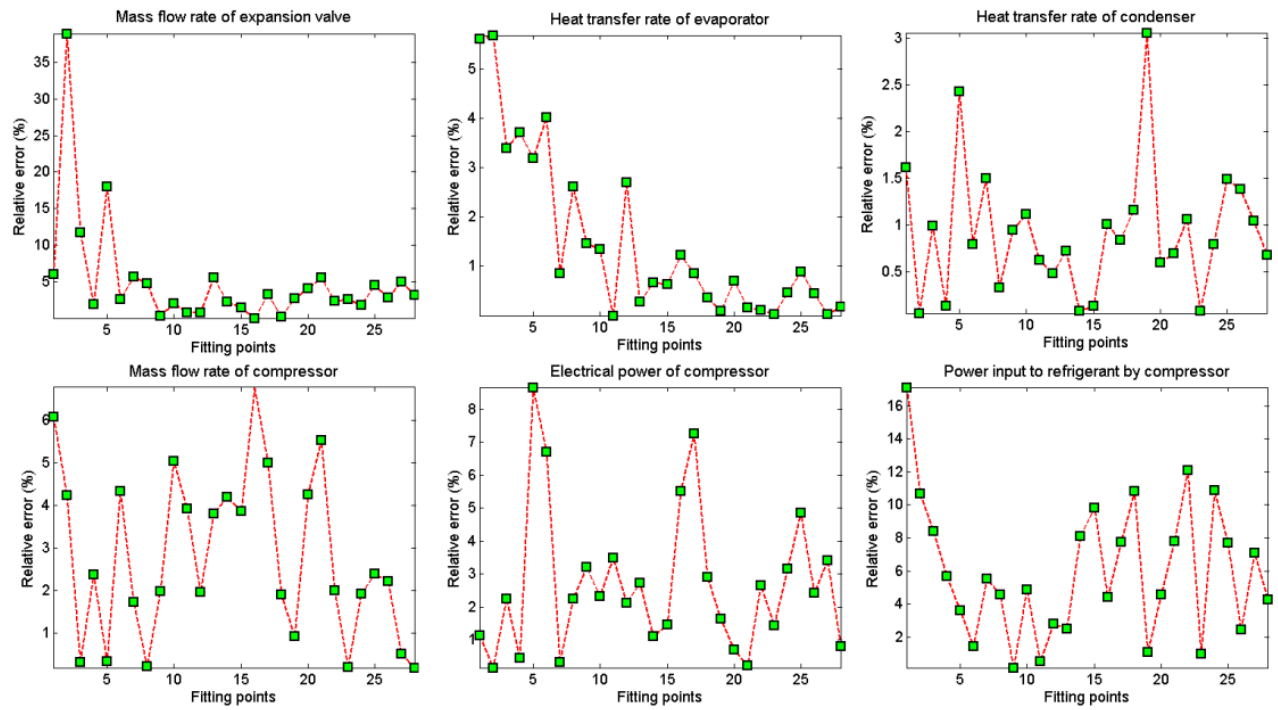

Fig. 8. Relative errors of component model validation

Table 4. Performance indices for component model validation

\begin{tabular}{|c|c|c|c|c|c|c|c|}
\hline Variable & $\begin{array}{c}\dot{m}_{r} \\
\text { (valve) }\end{array}$ & $\dot{Q}_{e}$ & $\dot{Q}_{c}$ & $\begin{array}{c}\dot{m}_{r} \\
(\text { comp) }\end{array}$ & $\dot{W}_{\text {comp }}$ & $\dot{Q}_{\text {comp }}$ & $\dot{W}_{c, \text { fan }}$ \\
\hline$E_{R}(\%)$ & 5.00 & 1.49 & 0.93 & 2.79 & 2.09 & 5.99 & 1.77 \\
\hline$E_{R M S}$ & 8.98 & 2.43 & 1.14 & 3.51 & 2.75 & 7.21 & 1.32 \\
\hline$R^{2}(\%)$ & 87.83 & 99.18 & 99.68 & 97.00 & 95.52 & 87.02 & 99.1 \\
\hline
\end{tabular}




\subsection{Global VCRC model validation}

After separately validating the component models of the system, a global validation of the VCRC model is performed in order to check its accuracy. From the proposed procedure explained in section 2.4 , the 82 experimental stationary state points are simulated using the cooling demand, i.e, $\dot{Q}_{e}$, external conditions $\left(T_{c, s e c, i}, T_{\text {surr }}\right.$ and $\left.\dot{m}_{e, s e c}\right)$ set-point variables $\left(T_{e, s e c, i}, S H\right.$ and $\left.P_{c}\right)$ as imposed variables. The values of constraints $\Delta T_{e, \min }$ and $\Delta T_{c, \text { min }}$ are set to 2.5 and 10, respectively. The obtained simulated values for the rest of the dependent variables are compared with the experimental data. Table 5 collects the mean relative absolute errors $\bar{E}_{R}$ of the main cycle variables. The standard deviations $\sigma\left(\bar{E}_{R}\right)$ of these relative errors are also shown. These values are under $5 \%$ in most variables and the global mean relative absolute error of the system is about 4\%, which indicates that the proposed VCRC model is enough accurate for engineering applications.

Table 5. Mean relative errors and standard deviations for the global validation of the VCRC model

\begin{tabular}{|c|c|c|c|c|c|c|c|c|c|c|c|c|c|c|}
\hline Variable & $A_{v}$ & $h_{e, r, o}$ & $h_{c, r, i}$ & $h_{c, r, o}$ & $\dot{m}_{r}$ & $\dot{m}_{c, s e c}$ & $N$ & $P_{e}$ & $\dot{Q}_{c}$ & $\dot{Q}_{c o m p}$ & $S C$ & $T_{c, r, i}$ & $\dot{W}_{\text {comp }}$ & $\dot{W}_{c, f a n}$ \\
\hline $\bar{E}_{R}(\%)$ & 3.98 & 0.15 & 0.58 & 0.68 & 1.19 & 7.59 & 7.40 & 6.66 & 1.56 & 6.60 & 7.48 & 3.42 & 3.99 & 6.35 \\
\hline$\sigma\left(\bar{E}_{R}\right)$ & 4.21 & 0.12 & 0.39 & 0.51 & 1.08 & 6.12 & 4.64 & 4.73 & 1.35 & 5.41 & 5.80 & 2.37 & 2.49 & 7.29 \\
\hline
\end{tabular}

\section{APPLICATION EXAMPLE}

The VCRC model can be used to evaluate the operation of the cooling system under different stationary state conditions. Next, two steady-state operation points are studied as illustrative examples in more detail. The environmental and demand conditions of these two points (point 1 and point 2) are listed in Table 6, as imposed variables. In this table, the data provided by simulation are associated to the point number with subscript sim, and the corresponding experimental results, with subscript exp. Initially, the set-points of the control loops of $S H$ and $P_{c}$ are set to $7{ }^{\circ} \mathrm{C}$ and 11.217 bar (10.2 barg), respectively, for point 1 ; and $10 \mathrm{C}^{\mathrm{o}}$ and 12.517 (11.5 barg) bar for point 2. With this previous information and the proposed VCRC model, the simulated cycles provided by the proposed method are depicted in Fig. 9 as well as the corresponding experimental cycles achieved operating the plant in the same conditions. Other dependent variables of the cycle are also shown in Table 6, where the "Main dependent variables" column constitutes a subset of the VCRC model solution that defines a specific cycle along with the set-points of selected controlled variables $\left(S H\right.$ and $\left.P_{c}\right)$. In addition, $\dot{W}_{c, \text { fan }}$ is included in the same column, which is calculated by means of Eq. (8). 

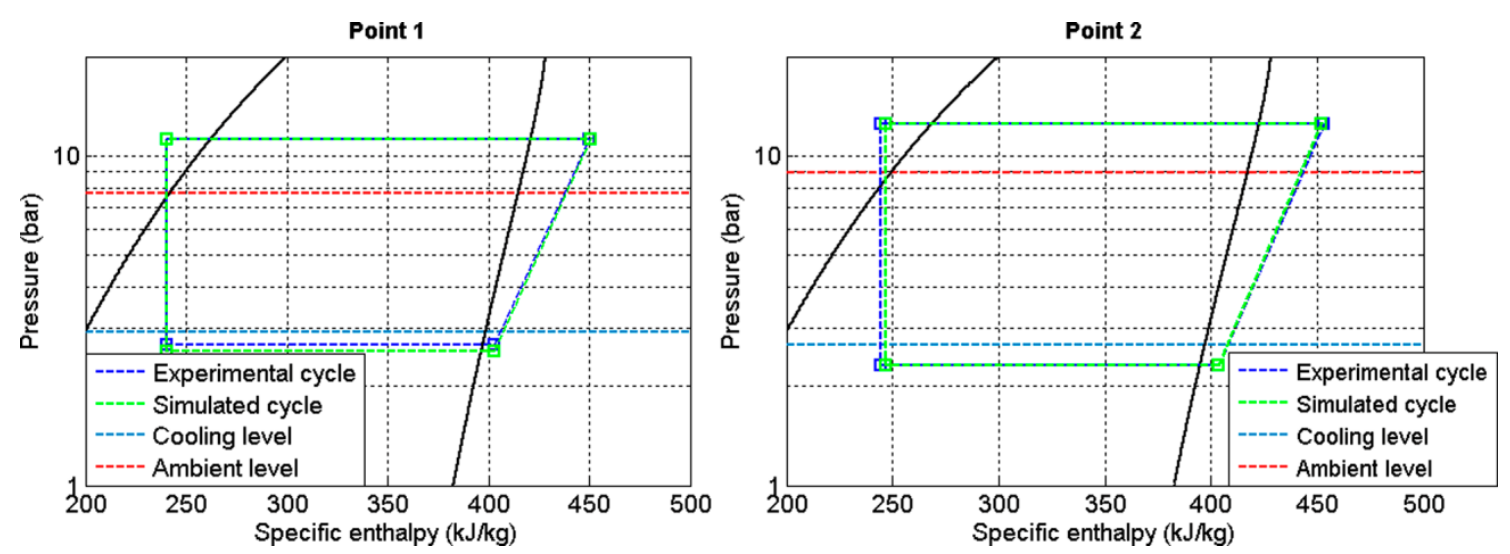

Fig. 9. Simulated and experimental cycles of examples for initial set-points

There is a good fit in both cases with no important errors, which was expected according to the global validation results. It is important to note that the set-points of the control loops of $S H$ and $P_{c}$ have been chosen as representative points within the valid operation range. The control loop set-point of $T_{e, s e c, i}$ is assumed to be not tunable since it is considered as an imposed demand requirement. However, there could be other different sets of references of $S H$ and $P_{c}$ that operate the plant in the same environmental and demand conditions although consuming different power.

Table 6. Main cycle variables of application examples

\begin{tabular}{|c|c|c|c|c|c|c|c|c|c|c|c|c|c|c|c|}
\hline \multirow{2}{*}{ Point } & \multicolumn{5}{|c|}{ Imposed variables } & \multicolumn{2}{|c|}{$\begin{array}{c}\text { Selected } \\
\text { set-points }\end{array}$} & \multicolumn{8}{|c|}{ Main dependent variables } \\
\hline & $T_{\text {surr }}$ & $T_{c, s e c, i}$ & $\dot{m}_{e, s e c}$ & $\dot{Q}_{e}$ & $T_{e, s e c, i}$ & $P_{c}$ & SH & $\dot{m}_{r}$ & $h_{e, r, i}$ & $h_{c, r, i}$ & $P_{e}$ & $\dot{W}_{\text {comp }}$ & $\dot{W}_{c, f a n}$ & $T_{c, r, i}$ & COP \\
\hline $1_{\text {sim }}$ & \multirow{4}{*}{27.37} & \multirow{4}{*}{30} & \multirow{4}{*}{0.228} & \multirow{4}{*}{2.04} & \multirow{4}{*}{0} & \multirow{2}{*}{11.22} & \multirow{2}{*}{7} & $12.5 \cdot 10^{-3}$ & 240.43 & 450.38 & 2.54 & 0.72 & 0.37 & 70.3 & 1.87 \\
\hline $1_{\text {exp }}$ & & & & & & & & $12.6 \cdot 10^{-3}$ & 240.59 & 449.74 & 2.68 & 0.70 & 0.66 & 69.7 & 1.51 \\
\hline $1_{\text {sim }}^{*}$ & & & & & & \multirow{2}{*}{11.90} & \multirow{2}{*}{6} & $12.6 \cdot 10^{-3}$ & 240.90 & 450.37 & 2.57 & 0.74 & 0.33 & 71.3 & 1.91 \\
\hline $1_{\text {exp }}^{*}$ & & & & & & & & $11.6 \cdot 10^{-3}$ & 243.33 & 453.17 & 2.53 & 0.71 & 0.33 & 74.4 & 1.96 \\
\hline 2 sim & \multirow{4}{*}{22.9} & \multirow{4}{*}{35} & \multirow{4}{*}{0.224} & \multirow{4}{*}{1.66} & \multirow{4}{*}{-2.5} & \multirow{2}{*}{12.52} & \multirow{2}{*}{10} & $10.6 \cdot 10^{-3}$ & 247.20 & 451.84 & 2.31 & 0.71 & 0.45 & 73.6 & 1.43 \\
\hline 2 exp & & & & & & & & $10.5 \cdot 10^{-3}$ & 244.55 & 453.09 & 2.31 & 0.72 & 0.61 & 74.8 & 1.25 \\
\hline $2_{\text {sim }}^{*}$ & & & & & & \multirow{2}{*}{13.6} & \multirow{2}{*}{5} & $10.8 \cdot 10^{-3}$ & 247.69 & 450.85 & 2.37 & 0.72 & 0.35 & 74.3 & 1.55 \\
\hline $2_{\text {exp }}^{*}$ & & & & & & & & $10.8 \cdot 10^{-3}$ & 249.63 & 453.43 & 2.63 & 0.69 & 0.32 & 76.7 & 1.64 \\
\hline
\end{tabular}

Therefore, from a practical point of view, a more interesting application of the VCRC model is determining the optimal set-points that achieve the cooling demand working in the same imposed conditions and minimizing the electrical power. Traditionally, this effectiveness is measured by means of the electrical COP which, is defined as follows

$C O P=\frac{\dot{Q}_{e}}{\dot{W}_{c o m p}+\dot{W}_{c, f a n}}$

where the denominator represents the total electrical power absorbed by the system. In the described experimental plant, it equals to the sum of the power consumptions of the compressor and the condenser fan.

For same cooling power demand, higher COP values imply operating the plant with lower electrical power consumptions. Next, the developed VCRC model is used to search for the optimal tunable set-points that maximize the COP for the imposed conditions and requirements of the previous two example points. The values of the aforementioned experimental cycles can be used as initial values for the dependent variables. Then, the VCRC model is solved for 
different pairs of $S H$ and $P_{c}$ references within their respective ranges according to Table 1 . When an acceptable cycle is provided, the corresponding COP value is calculated using (30). In this way, it is possible to obtain the surface of COP values for the different pairs of $S H$ and $P_{C}$ set-points for the imposed conditions at point 1 and point 2. These COP surfaces are shown in Fig. 10.

From the previous calculations, the pair of $S H$ and $P_{c}$ references that maximizes the COP values for each steady-state cycle is selected as optimal solution. For each point, this pair is highlighted in Fig. 10 using a black dot (Max. COP); and the original pair of set-points is also stressed as a blue dot (Original COP). The corresponding COP values and other dependent variables of these optimal cycles are listed in Table 6 with an asterisk as superscript. In addition, these simulated cycles have been also checked experimentally verifying a COP increase, as it is shown in Table 6. Although there are some differences between the COP value of these simulated and experimental cycles, a COP improvement is always achieved which implies energy savings and the consequent cost reduction and environmental enhancement. As shown in the last column of Table 6, the experimental COP is increased from 1.51 to 1.96 in the first analyzed point and from 1.25 to 1.64 in the second point. In terms of energy savings, the energy consumption is reduced about $24 \%$ for the two analyzed points.

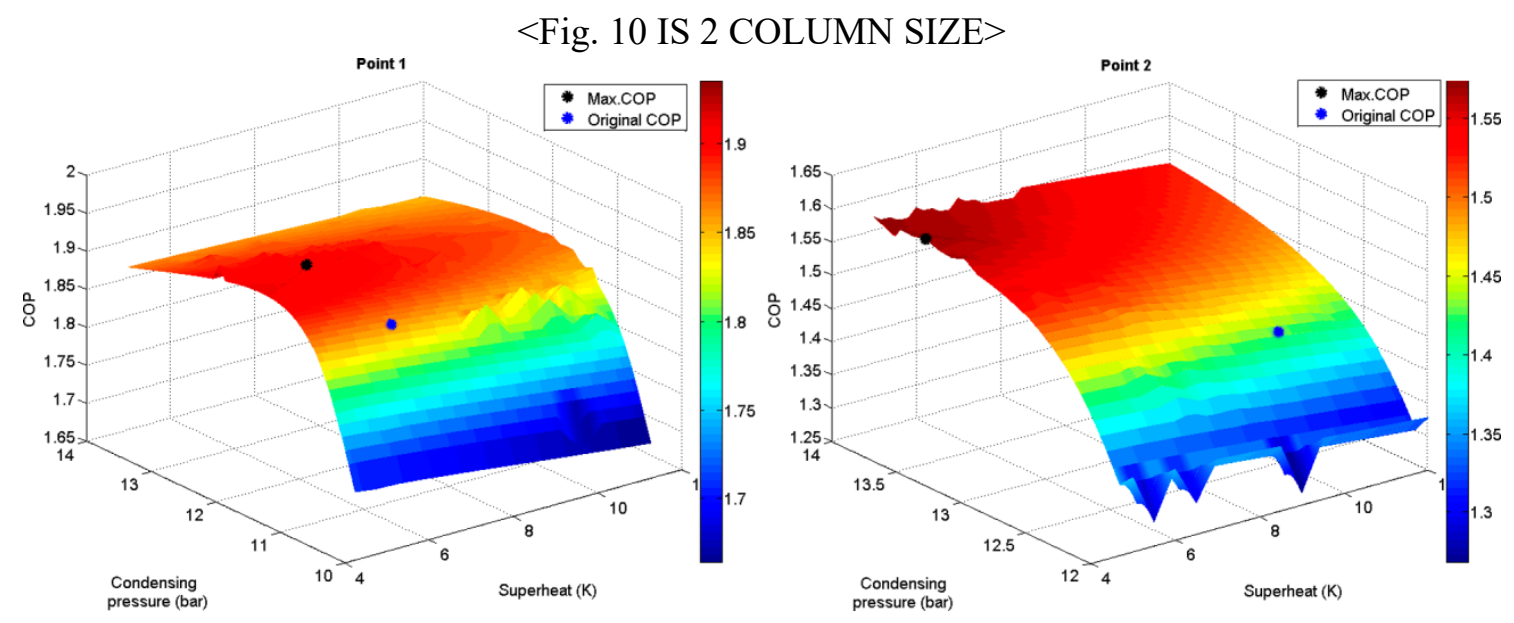

Fig. 10. COP estimated surfaces for the two representative points

\section{CONCLUSIONS}

In this work, a hybrid modelling approach for vapor compression refrigerant cycles was developed intending to achieve an optimal steady-state operation with regards to the total energy consumption. The global model of the refrigerant cycle has been proposed as a nonlinear constrained optimization problem that integrates the main component static models of different authors into the cost function and that is subjected to different constraints such as environmental conditions, required demands, mechanical limitations and two imposed variables. The proposed method has been verified in a real pilot plant, where the main application of interest has been demonstrated using the global model to improve the COP at various representative points of operation.

Identification and validation stages of the proposed model have been carried out through extensive experimental tests in the pilot plant. First, a parameter estimation and validation of the four main components of the real cycle have been separately carried out. Then, a global steady- 
state validation of the cycle has been performed obtaining average differences between simulated and experimental results below $10 \%$ in most of the dependent variables such as enthalpies and heat transfer rates. Due to the coherent and acceptable values generated by the proposed procedure, it has been employed offline to search for the optimal set-points of the control system that achieved the higher COP under different operating conditions in stationary state. The experimental results confirmed that the calculated references reduced the energy consumption.

The proposed VCRC block allows certain flexibility to modify the two variables that act as degrees of freedom and that need to be imposed for the resolution. In this paper, the superheat and the condenser pressure have been chosen for this purpose since they are variables controlled by decentralized control loops in the experimental process. However, the procedure is easily updated to the corresponding changes in the control structure. Future work will be addressed in this direction since other control configurations and controlled variables might allow a better cycle performance. Due to the accuracy and low computational cost of the hybrid models, it is also intended to use the developed VCRC model in real-time applications.

Acknowledgments

This work was supported by the Spanish Ministry of Economy and Competitiveness [grant DPI2012-37580-C02-01]. This support is gratefully acknowledged.

\section{REFERENCES}

[1] B.P. Rasmussen, A.G. Alleyne, Dynamic Modeling and Advanced Control of Air Conditioning and Refrigeration Systems, (2006).

[2] K. Wark, D.E. Richards, Thermodynamics, 6th ed., William C Brown Pub, 2000.

[3] L.O.S. Buzelin, S.C. Amico, J.V.C. Vargas, J.A.R. Parise, Experimental development of an intelligent refrigeration system, Int. J. Refrig. 28 (2005). doi:10.1016/j.ijrefrig.2004.08.013.

[4] L. Zhao, W. Cai, X. Ding, W. Chang, Model-based optimization for vapor compression refrigeration cycle, Energy. 55 (2013). doi:10.1016/j.energy.2013.02.071.

[5] L. Zhao, W.-J. Cai, X.-D. Ding, W.-C. Chang, Decentralized optimization for vapor compression refrigeration cycle, Appl. Therm. Eng. 51 (2013). doi:10.1016/j.applthermaleng.2012.10.001.

[6] K.A. Jahangeer, A.A.O. Tay, M. Raisul Islam, Numerical investigation of transfer coefficients of an evaporatively-cooled condenser, Appl. Therm. Eng. 31 (2011). doi:10.1016/j.applthermaleng.2011.02.007.

[7] US Environmental Protection Agency, National Action Plan for Energy Efficiency: Sector Collaborative on Energy Efficiency Accomplishments and Next Steps, (n.d.). http://www.epa.gov/cleanenergy/documents/\%0Asuca/sector_collaborative.pdf.

[8] Y. Suzuki, Y. Yamaguchi, K. Shiraishi, D. Narumi, Y. Shimoda, Analysis and modeling of energy demand of retail stores, in: Proc. Build. Simul. 2011 12th Conf. Int. Build. Perform. Simul. Assoc., 2011.

[9] J.B. Jensen, S. Skogestad, Optimal operation of simple refrigeration cycles. Part I: Degrees of freedom and optimality of sub-cooling, Comput. Chem. Eng. 31 (2007). doi:10.1016/j.compchemeng.2006.12.003. 
[10] N. Jain, A.G. Alleyne, A framework for the optimization of integrated energy systems, Appl. Therm. Eng. 48 (2012). doi:10.1016/j.applthermaleng.2012.04.003.

[11] H. Rasmussen, L.F.S. Larsen, Non-linear and adaptive control of a refrigeration system, IET Control Theory Appl. 5 (2011). doi:10.1049/iet-cta.2009.0156.

[12] L.S. Larsen, C. Thybo, Potential energy savings in refrigeration systems using optimal set-points, in: Proc. IEEE Int. Conf. Control Appl., 2004.

[13] G. Bejarano, D. Rodríguez, J.A. Alfaya, M.G. Ortega, F. Castaño, On identifying steadystate parameters of an experimental mechanical-compression refrigeration plant, Appl. Therm. Eng. 109 (2016). doi:10.1016/j.applthermaleng.2016.08.021.

[14] X. Jia, C.P. Tso, P. Jolly, Y.W. Wong, Distributed steady and dynamic modelling of dryexpansion evaporators, Int. J. Refrig. 22 (1999).

[15] H. Wang, S. Touber, Distributed and non-steady-state modelling of an air cooler, Int. J. Refrig. 14 (1991). doi:10.1016/0140-7007(91)90082-R.

[16] M.W. Browne, P.K. Bansal, An elemental NTU- $\varepsilon$ model for vapour-compression liquid chillers, Int. J. Refrig. 24 (2001). doi:10.1016/S0140-7007(00)00091-8.

[17] M.W. Browne, P.K. Bansal, Steady-state model of centrifugal liquid chillers, Int. J. Refrig. 21 (1998).

[18] M.L. Martins Costa, J.A.R. Parise, A three-zone simulation model for a air-cooled condensers, Heat Recover. Syst. CHP. 13 (1993). doi:10.1016/0890-4332(93)90029-U.

[19] Y.G. Yohanis, O.S. Popel, S.E. Frid, A simplified method of calculating heat flow through a two-phase heat exchanger, Appl. Therm. Eng. 25 (2005). doi:10.1016/j.applthermaleng.2004.12.011.

[20] Y.T. Ge, R. Cropper, Performance evaluations of air-cooled condensers using pure and mixture refrigerants by four-section lumped modelling methods, Appl. Therm. Eng. 25 (2005). doi:10.1016/j.applthermaleng.2004.10.001.

[21] Y. Ge, R. Cropper, Air-cooled condensers in retail systems using R22 and R404A refrigerants, Appl. Energy. 78 (2004). doi:10.1016/S0306-2619(03)00155-7.

[22] N.T. Russell, H.H.C. Bakker, Modular modelling of an evaporator for long-range prediction, Artif. Intell. Eng. 11 (1997).

[23] N.T. Russell, H.H.C. Bakker, R.I. Chaplin, A comparison of dynamic models for an evaporation process, Chem. Eng. Res. Des. 78 (2000). doi:10.1205/026387600528274.

[24] X. Ding, W. Cai, L. Jia, C. Wen, Evaporator modeling - A hybrid approach, Appl. Energy. (2009). doi:10.1016/j.apenergy.2008.04.005.

[25] X. Ding, L. Jia, W. Cai, C. Wen, G. Zhang, A hybrid modeling for the real-time control and optimization of compressors, in: 2009: pp. 3256-3261. doi:10.1109/ICIEA.2009.5138804.

[26] Y.-W. Wang, W.-J. Cai, Y.-C. Soh, S.-J. Li, L. Lu, L. Xie, A simplified modeling of cooling coils for control and optimization of HVAC systems, Energy Convers. Manag. 45 (2004). doi:10.1016/j.enconman.2003.12.024.

[27] M. Gümüş, M. Atmaca, A.T. Inan, T. Yilmaz, Optimization of irreversible cogeneration systems under alternative performance criteria, Int. J. Thermophys. 30 (2009). doi:10.1007/s10765-009-0621-3.

[28] M. Gümüş, M. Atmaca, Energy and exergy analyses applied to a CI engine fueled with diesel and natural gas, Energy Sources, Part A Recover. Util. Environ. Eff. 35 (2013). doi:10.1080/15567036.2010.516312. 
[29] G. Bejarano, J.A. Alfaya, M.G. Ortega, M. Vargas, On the difficulty of globally optimally controlling refrigeration systems, Appl. Therm. Eng. 111 (2017). doi:10.1016/j.applthermaleng.2016.10.007.

[30] X. Ding, W. Cai, L. Jia, C. Wen, G. Zhang, A hybrid condenser model for real-time applications in performance monitoring, control and optimization, Energy Convers. Manag. 50 (2009). doi:10.1016/j.enconman.2009.02.014.

[31] L.C. Schurt, C.J.L. Hermes, A.T. Neto, A model-driven multivariable controller for vapor compression refrigeration systems, 32 (2009) 1672-1682. doi:10.1016/j.ijrefrig.2009.04.004.

[32] I.H. Bell, J. Wronski, S. Quoilin, V. Lemort, Pure and pseudo-pure fluid thermophysical property evaluation and the open-source thermophysical property library coolprop, Ind. Eng. Chem. Res. 53 (2014). doi:10.1021/ie4033999.

[33] M.A. Wolfe, Numerical methods for unconstrained optimization : an introduction, Van Nostrand Reinhold, New York, 1978.

[34] L.C. Schurt, C.J.L. Hermes, A. Trofino Neto, Assessment of the controlling envelope of a model-based multivariable controller for vapor compression refrigeration systems, Appl. Therm. Eng. 30 (2010). doi:10.1016/j.applthermaleng.2010.02.024.

[35] J. Winkler, V. Aute, R. Radermacher, Comprehensive investigation of numerical methods in simulating a steady-state vapor compression system, Int. J. Refrig. 31 (2008). doi:10.1016/j.ijrefrig.2007.08.008.

[36] G. -1. Ding, Recent developments in simulation techniques for vapour-compression refrigeration systems, Int. J. Refrig. 30 (2007). doi:10.1016/j.ijrefrig.2007.02.001.

[37] D.L. Blanco, K. Nagano, M. Morimoto, Steady state vapor compression refrigeration cycle simulation for a monovalent inverter-driven water-to-water heat pump with a desuperheater for low energy houses, Int. J. Refrig. 35 (2012). doi:10.1016/j.ijrefrig.2012.07.005.

[38] R.A. Waltz, J.L. Morales, J. Nocedal, D. Orban, An interior algorithm for nonlinear optimization that combines line search and trust region steps, Math. Program. 107 (2006). doi:10.1007/s10107-004-0560-5.

[39] M.L. Ruz, S. Fragoso, F. Vázquez, R.D. Rodríguez, F. Morilla, J. Garrido, Planta experimental para supervisión y control del ciclo de refrigeración por compresión de vapor, in: XXXVII Jornadas de Automática, CEA-IFAC, Madrid (Spain), 2016. 